\title{
Article \\ Differential Gene Expression in the Heads of Behaviorally Divergent Culex pipiens Mosquitoes
}

\author{
Anna Noreuil and Megan L. Fritz *(D) \\ Department of Entomology, University of Maryland, College Park, MD 20742, USA; anoreuil@umd.edu \\ * Correspondence: mfritz13@umd.edu
}

Simple Summary: Host preference has profound impacts on the epidemiology of mosquito-borne disease transmission, yet much is still unknown about the molecular basis for these preferences. Here, we examined host preference in the West Nile virus vector, Culex pipiens. We examined human and avian landing rates for eight populations: five originating from above- and three from belowground breeding and overwintering habitats. While above-ground populations tended to be biased toward avian landing and below-ground populations tended toward human landing, a range of behaviors was observed, consistent with other mosquito species. Patterns of differential expression and splice site variation were measured for one avian- and one human-seeking population as a first step toward identifying genes involved in regulation of blood feeding behaviors as well as differences in host preference. We conclude with a discussion of specific differentially expressed genes and their potential to influence host seeking behaviors of $C x$. pipiens females.

Citation: Noreuil, A.; Fritz, M.L. Differential Gene Expression in the Heads of Behaviorally Divergent Culex pipiens Mosquitoes. Insects 2021, 12, 271. https://doi.org/10.3390/ insects12030271

Academic Editors: Igor Sharakhov and Robert M. Waterhouse

Received: 2 March 2021

Accepted: 15 March 2021

Published: 23 March 2021

Publisher's Note: MDPI stays neutral with regard to jurisdictional claims in published maps and institutional affiliations.

Copyright: (C) 2021 by the authors. Licensee MDPI, Basel, Switzerland. This article is an open access article distributed under the terms and conditions of the Creative Commons Attribution (CC BY) license (https:// creativecommons.org/licenses/by/ $4.0 /)$.

\begin{abstract}
Host preferences of $C x$. pipiens, a bridge vector for West Nile virus to humans, have the potential to drive pathogen transmission dynamics. Yet much remains unknown about the extent of variation in these preferences and their molecular basis. We conducted host choice assays in a laboratory setting to quantify multi-day human and avian landing rates for $C x$. pipiens females. Assayed populations originated from five above-ground and three below-ground breeding and overwintering habitats. All three below-ground populations were biased toward human landings, with rates of human landing ranging from $69-85 \%$. Of the five above-ground populations, four had avian landing rates of $>80 \%$, while one landed on the avian host only $44 \%$ of the time. Overall response rates and willingness to alternate landing on the human and avian hosts across multiple days of testing also varied by population. For one human- and one avian-preferring population, we examined patterns of differential expression and splice site variation at genes expressed in female heads. We also compared gene expression and splice site variation within human-seeking females in either gravid or host-seeking physiological states to identify genes that may regulate blood feeding behaviors. Overall, we identified genes with metabolic and regulatory function that were differentially expressed in our comparison of gravid and host-seeking females. Differentially expressed genes in our comparison of avian- and human-seeking females were enriched for those involved in sensory perception. We conclude with a discussion of specific sensory genes and their potential influence on the divergent behaviors of avian- and human-seeking $C x$. pipiens.
\end{abstract}

Keywords: Culex pipiens; host preference; RNA sequencing; gene expression; whole heads; sensory genes

\section{Introduction}

Vertebrate blood meals are required by most mosquito species for reproduction. While this requirement is broadly shared across mosquito taxa, the vertebrate class or species from which females acquire blood is not. Host preference, or preferential feeding on one vertebrate host over others, varies between and even within mosquito species [1]. Preferential feeding behavior has profound impacts on mosquito-borne disease transmission [2]; 
yet despite its epidemiological importance, large gaps still exist in our knowledge of its underlying molecular and physiological mechanisms.

When seeking a host, mosquitoes must detect and respond to host cues, which vary over space and time in their environment. Such cues include carbon dioxide $\left(\mathrm{CO}_{2}\right)$, visual appearance, local increases in temperature and humidity, and odors emitted from skin and breath [3-6]. Integration of multiple sensory modalities during host-seeking allows mosquitoes to respond to long-, mid-, and short-range host cues [5,6]. At long range, stimulation with $\mathrm{CO}_{2}$ activates host-seeking behavior, allows females to orient toward and locate a host, and heightens responses to host-associated visual stimuli [7-12]. At closer range, a $\mathrm{CO}_{2}$ stimulus increases sensitivity of the olfactory system to skin odors [13]. Host body heat and humidity guide landing [14], while skin odors are thought to ultimately determine host acceptance [6,15].

Detection of heat, humidity, $\mathrm{CO}_{2}$, and odor cues relies upon receptors expressed along the dendrites of neurons, which are housed in porous sensory hairs covering the antennae, maxillary palps, and labellum $[16,17]$. Thermoreceptor proteins, including TRPA1, which is expressed along the dendrites of neurons in thermosensitive sensory hairs, aid in detection of host body heat and direct movement toward hosts [18]. Chemoreceptors expressed along olfactory receptor neurons (ORNs) include odorant receptors (ORs) co-expressed with an essential co-receptor orco, and ionotropic receptors (IRs), both of which detect volatiles in the air. Upon entering pores in the sensory hairs, some host volatiles become bound to odorant-binding proteins (OBPs), which either chaperone the odor molecules to their respective receptors or act to degrade them $[19,20]$. $\mathrm{CO}_{2}$ perception, taste, and contact sensation are mediated by gustatory receptors (GRs), which are also expressed on ORNs and other non-ORNs $[16,21]$. Binding of host-specific odor molecules and tastants to their chemosensory receptors produces electrophysiological signals, which are sent to and processed in the central nervous system, determining responsiveness to a host [6,15].

The mosquito, Culex pipiens, is the primary vector of West Nile virus (WNV) in Eastern North America and exists as two morphologically identical bioforms: molestus and true pipiens [22]. These forms vary with respect to multiple physiological and behavioral traits, reportedly including blood host preference (Table 1). Form pipiens is thought to be predominately avian-seeking, while form molestus is thought to be mammalian-, and sometimes human-seeking [23-25]. In nature, the two forms can hybridize where populations come into contact with one another [26-30]. Molestus-pipiens F1 hybrids display indiscriminate feeding behaviors when tested in a laboratory setting, while progeny of F1s backcrossed to molestus or pipiens have host responses biased toward that of their non-hybrid parent, indicating a genetic basis for this trait [23].

Table 1. Differences in behavioral and physiological traits for the pipiens and molestus bioforms of the northern house mosquito, Culex pipiens.

\begin{tabular}{|c|c|c|c|}
\hline Trait & Form Pipiens & Form Molestus & Citations \\
\hline Overwintering behavior & Diapausing. & Does not diapause. & [31-35] \\
\hline Breeding site & $\begin{array}{l}\text { Breeds in above-ground } \\
\text { aquatic habitats. }\end{array}$ & $\begin{array}{l}\text { Breeds in below-ground } \\
\text { aquatic habitats. }\end{array}$ & [36-40] \\
\hline Mating behavior & Mates in swarms above ground. & $\begin{array}{l}\text { Mates below ground in } \\
\text { confined spaces. }\end{array}$ & {$[22,26,39,41,42]$} \\
\hline Reproduction & $\begin{array}{l}\text { Requires a blood meal for egg } \\
\text { production in the first gonotrophic } \\
\text { cycle (anautogeny). }\end{array}$ & $\begin{array}{l}\text { Does not require a blood meal for egg } \\
\text { production in the first gonotrophic } \\
\text { cycle (facultative autogeny). }\end{array}$ & [43-46] \\
\hline Host preference & Primarily avian-seeking. & Primarily mammal-seeking. & {$[23,47-56]$} \\
\hline
\end{tabular}

Here, we acquired eight populations of North American $C x$. pipiens, collected from previously described above-ground form pipiens breeding and over-wintering sites and belowground form molestus breeding sites (Table 1 and Table S1). Hereafter, we refer to these populations with respect to where they were collected rather than bioform nomenclature 
because it is known that gene flow can occur between the forms in North America [27,30]. We used a multi-day host choice assay to quantify the extent of variation in human and avian host preference among above- and below-ground $C x$. pipiens and tested for differences between populations. As a first step toward elucidating the molecular basis for host preference in this species, we used RNA sequencing to quantify gene expression differences in the heads of one avian- and one human-seeking population. Population-level differences in gene expression between human- and avian-seeking females may shed light on genes that contribute to observed differences in host preference.

The molestus form of $C x$. pipiens is facultatively autogenous, or able to produce an egg raft in their first gonotrophic cycle without blood feeding (Table 1). Within days of pupal emergence, females enter a gravid physiological state [43]. After deposition of their first egg raft, however, females must seek a host to acquire blood for subsequent reproductive events. The human-seeking below-ground population used in our RNA sequencing experiment was also facultatively autogenous. For this population, we included heads of both gravid females that do not host-seek [57-59] and parous females that do as separate treatments in our RNA sequencing experiment. We then compared gene expression profiles of humanseeking females in different physiological states to determine whether any differentially expressed genes could be involved in the regulation of blood feeding behaviors as females transition from a gravid to parous host-seeking state.

\section{Materials and Methods}

\subsection{Mosquito Populations}

Eight $C x$. pipiens populations were collected from above-ground (AG) or belowground (BG) breeding sites in North America (Table S1). Five were initiated from either diapausing adults collected from AG hibernacula or egg rafts collected from AG breeding sites in three different metropolitan areas: Chicago, IL ( $\mathrm{n}=3$; called AG1-AG3), Laurel, MD ( $\mathrm{n}=1$; AG4), and New York City, NY ( $\mathrm{n}=1$; AG5). The remaining three were derived from eggs, larvae, and adults captured in two collection events at BG breeding sites in Calumet, IL ([37]; BG1 and BG2) and Stinson Beach, CA (BG3). All mosquito populations were reared identically throughout the course of our study according to [23], with exception of the blood feeding regime. AG populations were fed 9 parts Na-heparinated goose blood sweetened with 1 part $50 \%$ sucrose solution twice per generation for egg production. All BG populations were facultatively autogenous and did not require blood feeding for egg production in their first gonotrophic cycle. Therefore, they were not offered blood to support colony egg production during our study.

\subsection{Host Landing Assay}

To quantify the extent of variation in host preference across multiple AG and BG populations of $C x$. pipiens, we used the multi-day landing assay described by Fritz et al. [23]. In brief, an unrestrained two- to three-week-old chicken (Gallus domesticus) and the unwashed hand of a 24-year-old white female investigator rested opposite one another on platforms in a circular behavioral arena. A $50 \mathrm{~g}$ block of dry ice was placed under each platform, each with a $1 \mathrm{~cm}$ diameter hole, allowing for release of $\mathrm{CO}_{2}$ into the arena at a mean hourly rate of ca. $258 \mathrm{~mL} / \mathrm{min}$. This release rate falls within the acceptable range for host attraction for both human- and avian-seeking mosquito species [60]. Host positions in the arena were alternated between testing days, and the investigator also alternated the hand (i.e., right or left) offered each day. Multiple chicks $(\mathrm{N}=62)$ were used throughout the course of the experiment, but individual mosquitoes were always exposed to the same chick across testing days.

Prior to testing, females were allowed to mate and age in $30 \times 30 \times 30 \mathrm{~cm}$ white Bugdorm-1 cages (MegaView Science Co. Ltd., Taiwan). We confirmed that the behavior of BG1 females at two and three weeks post-emergence (PE) did not differ (see Supplemental Methods), which allowed us to wait one extra week PE for deposition of autogenous egg rafts in BG populations. Thereafter, AG females were always tested at two weeks PE, while 
BG females were tested at three weeks PE. All mosquitoes were offered a $10 \%$ sucrose solution and an ovipositional resource ad libitum prior to behavioral testing. For transfer into the behavioral arena, four to six females of a single population were collected in $20 \mathrm{~mL}$ glass scintillation vials by a gloved hand and held for no more than one hour. Upon release from their scintillation vials, females were monitored by two observers for $15 \mathrm{~min}$ or until all landed and tapped a host with the labellum. After landing on a host, but prior to blood feeding, females were removed from the arena by mouth aspirator. All females that responded to a host on day one of testing were held individually in scintillation vials with access to $10 \%$ sucrose and tested again on each of two subsequent days.

\subsection{Chicken vs. Human Choice Landing Assays: Data Analysis}

To analyze our landing assay data, we constructed mixed logistic regression models with binomial error structures using the lme4 package (v. 1.1-14) [61] in $\mathrm{R}$ (v. 3.3.2; $\mathrm{R}$ Foundation for Statistical Computing, Vienna, Austria). A statistically significant impact of the population on individual mosquito response was determined by model reduction, where models with and without the fixed effect of population were compared by likelihood ratio test (lmtest v. 0.9-35) [62]. Initially, we examined whether the overall response rate to any host varied by mosquito population on day one. A random effect of the "chick" was included in our model to account for inter-individual variation in attractiveness among avian hosts used in the assay $[63,64]$. Our full model examined the response by the $i$ th mosquito to the investigator's hand and/or the jth chick:

$$
\operatorname{Pr}\left[\mathrm{y}_{i}=1\right]=\operatorname{logit}^{-1}\left(\beta_{0 i j}+\beta_{1} \text { Population }_{i j}+u_{0 i j}\right)
$$

for $1 \leq i \leq n$ and $1 \leq j \leq m$ where $u_{0} \sim \mathrm{N}\left(0, \sigma^{2}\right)$ represents the random effect of the chick.

This analysis was performed three times: (1) for all populations examined in our behavioral assay, (2) for populations from AG collections only, and (3) for populations from BG collections only.

We then examined whether human host acceptance varied by mosquito population over multiple days of testing. For this, landing events on the human and chick were scored as 1 and 0 , respectively. Two fixed effects were considered in the full model: (1) the population from which the mosquito originated, and (2) the day, corresponding to days one through three of testing, which accounted for repeated measurement of individuals. Our full model examined the response by the $i$ th mosquito to the investigator's hand and/or the $j$ th chick:

$$
\operatorname{Pr}\left[\mathrm{y}_{i}=1\right]=\operatorname{logit}^{-1}\left(\beta_{0 i j}+\beta_{1} \text { Population }_{i j}+\beta_{2} \text { Day }_{i j}+u_{0 i j}\right)
$$

for $1 \leq i \leq n$ and $1 \leq j \leq m$

where $u_{0} \sim \mathrm{N}\left(0, \sigma^{2}{ }_{\mathrm{j}}\right)$ represents the random effect of the chick.

This model was also run 3 times, as described above-once for all populations, once for AG, and once for BG populations- to quantify within and between collection site variation.

Finally, we examined whether the probability of host-switching for an individual female varied according to population. Individuals that switched hosts at least once per multi-day testing period were scored as a 1 , and individuals who did not switch hosts but responded at least twice were given a score of 0 . Individuals that failed to respond on multiple days were not included in this analysis. Our full model examined the effect of the population on host switching by the $i$ th mosquito, as follows:

$$
\operatorname{Pr}\left[\mathrm{y}_{i}=1\right]=\operatorname{logit}^{-1}\left(\beta_{0 i}+\beta_{1} \text { Population }_{i}+u_{0 i}\right)
$$

for $1 \leq i \leq n$

where $u_{0} \sim \mathrm{N}\left(0, \sigma^{2}\right)$. 
For this model comparison, we did not include a random effect of the chick, as for previous models. Many fewer mosquitoes responded during multiple days of testing, which reduced the number of observations per chick.

For all responses, which included overall response rates, host choice, and hostswitching, population means were calculated and presented alongside $95 \%$ non-parametric bootstrapped confidence intervals (CIs; $\mathrm{n}$ boots $=5000)$.

\subsection{RNA Sequencing of Mosquito Heads}

As a first step toward elucidating the molecular basis for differences in host-seeking behavior, we compared gene expression in the heads of avian-seeking AG2 females with human-seeking BG1 females. These two populations showed statistically significant differences in host acceptance behavior according to their non-overlapping 95\% CIs (Table S2). Using these populations, we generated three treatment groups: nulliparous AG2, parous BG1 females, which had deposited their first egg raft, and gravid BG1 females, who had yet to deposit their first raft. Mosquito rearing details for our RNA-seq experiment are included in the Supplemental Methods. Seven- to nine-day-old females were sacrificed at $-80{ }^{\circ} \mathrm{C}$ between two to six hours after the onset of scotophase, the time of day they are most likely to engage in host-seeking behavior [65]. Four replicate groups of 30 heads bearing intact chemosensory appendages (i.e., antennae, maxillary palps, and the labellum) were dissected on a small petri dish filled with dry ice for each treatment. Heads were held in sterile $1.5 \mathrm{~mL}$ microcentrifuge tubes containing Trizol and stored at $-80{ }^{\circ} \mathrm{C}$ until isolation of RNA by Zymo Direct-zol RNA MiniPrep (Zymo Research, Irvine, CA, USA). RNA quality values (RQI) were assessed by an Agilent 2100 Bioanalyzer (Agilent Technologies Inc., Santa Clara, CA, USA) prior to RNA-seq library preparation and were $>6.8$ for all pools (Table S3). Complementary DNA synthesis and Illumina Truseq Nano LT library preparation were conducted at the North Carolina State University Genomic Sciences Laboratory according to standard protocols, and indexed libraries were sequenced as 150 bp paired-end reads on a single Illumina NextSeq500 flow cell (Table S3).

\subsection{Read-Filtering and Quality Control}

We assessed read quality using FastQC v.0.11.5 [66] and then removed adapters as well as filter-trimmed reads based on Phred quality scores (Trimmomatic v.0.38) [67]. A sliding window approach was used for filter-trimming, where window size was set to 5 base pairs (bp), the Phred quality threshold was 20, and only properly paired reads at least $50 \mathrm{bp}$ in length were retained. Filtered-trimmed reads were aligned to the Culex quinquefasciatus reference genome (VectorBase version 2; 21 August 2019) using STAR v.2.7.6 [68] with ENCODE standard options. We counted aligned reads that met our threshold for mapping quality of 20 or higher using HTSeq-Count [69]. For our downstream analyses, we only considered genes with at least 10 reads mapped in at least 4 samples.

A principal component analysis (PCA) was used to examine sample-to-sample variation in gene expression profile, with the expectation that BG1 samples in different physiological states (gravid vs. parous) should be more similar to one another than BG1 samples were to the AG2 samples. Bayesian generalized linear models were developed with the arm package (v. 1.11-2) [70] to examine whether the top three principal components (PCs) could predict the population (BG1 vs. AG2) and physiological state (gravid vs. host-seeking) of our samples. PC prediction of population or physiological state was determined by simulating a posterior distribution for each PC coefficient in our models ( $n=10,000$ simulations) and calculating the $2.5 \%$ and $97.5 \%$ quantiles (i.e., $95 \%$ credible intervals). Overlap of these credible intervals with zero indicated that PC could not predict a sample's population or physiological state. Spearman's rank correlation coefficients were calculated to examine pairs of samples for gene expression profile correlation and confirm results from our PCA. 


\subsection{Differential Gene Expression Analysis}

We quantified differential gene expression (DGE) for each pairwise treatment comparison using DESeq2 [71]. A standard adaptive shrinkage estimator from the ashr package [72] was applied to our $\log _{2}$ fold change (FC) values to remove noise due to genes with low read counts. A gene was considered to be differentially expressed if the Benjamini and Hochberg adjusted $p$-value was $<0.05$ and the absolute shrunken $\log _{2}$ FC was 0.58 (1.5-FC) or greater. To determine whether these differentially expressed genes were associated with specific biological processes, we conducted an overrepresentation analysis with PANTHER (v. 15.0) [73]. Using GO-slim Biological Process annotations, we compared whether specific gene ontology categories were differentially expressed more often than expected for our overall gene set using a Fisher's exact test with a Benjamini-Hochberg correction for false discovery rate.

\subsection{Splice Site Variation}

To examine splice site variants for BG1 and AG2 populations, we used the splice junction output tables generated by STAR for each sample. We considered high-quality splice junctions to be those (1) present in all samples from a single population using (2) stranded read mappings at (3) annotated genes with (4) at least 100 mapped reads in all populations. We conducted pairwise comparisons between BG1 parous and BG1 gravid females as well as BG1 parous and AG2 females to identify high-quality putatively population-specific splice junctions as compared to the total splice junctions detected (i.e., present in any sample) in the alternate population. Population-specific splice junctions were compared with DGE results for each pairwise comparison to identify whether changes in expression were correlated with splice site variation. A Chi-squared test was used to determine whether the numbers of genes with population-specific splice junctions differed significantly for each pairwise comparison $(\alpha=0.05)$. These tests assumed that there were 7572 total genes in the BG1 gravid comparison to BG1 parous and 7480 total genes in the BG1 parous comparison to AG2 that met our filtering criteria above.

\subsection{Candidate Sensory Gene Identification}

For our analysis of sensory genes, we focused on the contrast between humanpreferring BG1 parous females and avian-preferring AG2 females because both treatments were in a physiological state compatible with host-seeking. Genes from families with known roles in chemosensation and perception of visual cues, and which could explain differences in host preference for these populations, were specifically examined for evidence of DGE. We identified the total numbers of detectable genes from the olfactory receptor (OR), ionotropic receptor (IR), gustatory receptor (GR), odorant binding protein (OBP), sensory neuron membrane protein (SNMP), and chemosensory protein (CSP) families as well as opsins involved in vision. This included any gene from these families with statistically significant differences in expression, regardless of FC. To identify whether these candidate genes were evolutionarily conserved among mosquito taxa, we identified their orthology group (OG) using the OrthoMCL database (v. 6.2) [74]. Genes considered to have significant protein sequence homology had alignment E-value cutoff scores of less than $1.0 \times 10^{-25}$. A subset of these genes with statistically significant differences in expression was validated by quantitative polymerase chain reaction (qPCR; see Supplemental Methods).

\section{Results}

3.1. Host Response Rates and Preferences of Cx. pipiens

3.1.1. Population-Level Day One Overall Response Rates

In total, the host acceptance behaviors of $686 \mathrm{AG}$ and $377 \mathrm{BG}$ females were assessed, and of these, 348 AG (50.7\%) and 221 BG (58.6\%) females accepted a host on day one. For one BG population, BG1, we examined both overall response and host acceptance rates for females at two and three weeks PE and found no statistically significant difference between them (Table S4). Therefore, all BG1 data, regardless of PE time, were pooled 
for subsequent behavioral analyses. Mean overall response rates on day one varied significantly according to population (d.f. $=7, \chi^{2}=26.8, p<0.0004$; Figure $1 \mathrm{~A}$, Table S2). The percentages of BG1, BG2, and BG3 females that responded to any host on day one were $64.9 \%, 56.5 \%$, and $50.0 \%$, respectively. These overall response rates did not vary significantly among BG populations (d.f. $=2, \chi 2=1.9, p=0.3962$ ). Yet among AG populations, the percentages of females that accepted a host on day one varied significantly (d.f. $=4$, $x^{2}=29.5, p<0.0001$ ), ranging from $28.0-75.8 \%$ (Table S2).

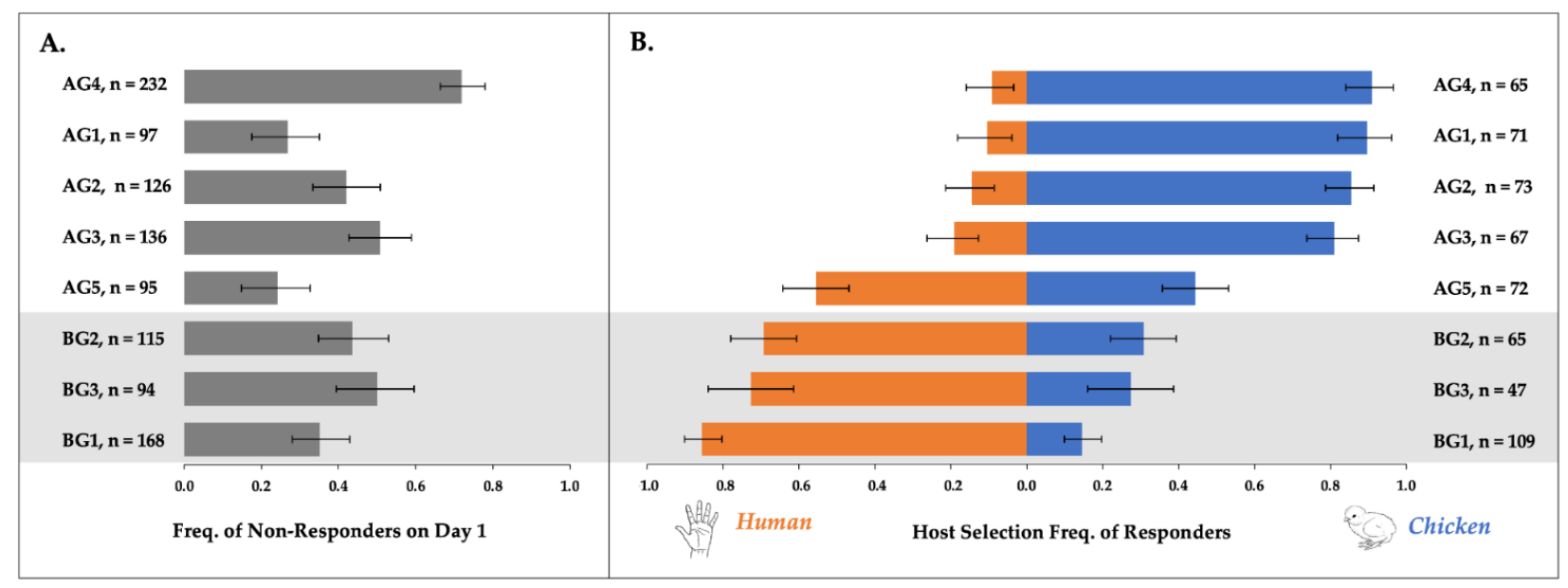

Figure 1. Observed response rates with bootstrapped 95\% confidence intervals $(n=5000)$ to human vs. chicken host for five above-ground and three below-ground populations of Culex pipiens. Panel (A) shows the frequency of non-responders on Day 1 , and $n=$ total number of mosquitoes assessed (d.f. $=7 ; \chi 2=26.8 ; p<0.0004)$. Panel (B) shows the frequency with which Day 1 responders (n) selected either a human or avian host in multi-day tests (d.f. $=7 ; \chi 2=143.46 ; p<0.0001$ ).

\subsubsection{Multi-Day Host Responses by Individual Females}

Multi-day responses to the human and avian hosts were quantified for all females that landed on any host on the first day of testing. Human host acceptance varied significantly among AG and BG populations (d.f. $=7, \chi 2=143.46, p<0.0001$; Figure 1B). All three BG populations were biased toward human landing, but the strength of the bias varied (d.f. $=2, \chi 2=8.9226, p=0.0116$ ): the percentages of human responses were $69.2 \%, 72.6 \%$, and $85.4 \%$, for BG2, BG3, and BG1, respectively. Four of the five AG populations were biased toward avian landing, with $>80 \%$ of females selecting the chicken. Avian response rates were $81.0 \%, 85.5 \%, 89.6 \%$, and $90.9 \%$ for AG populations AG3, AG2, AG1, and AG4, respectively. The strength of the bias did not differ among these four AG populations, based upon their overlapping $95 \%$ CIs. Females belonging to AG5, a population from New York, showed no clear patterns of host acceptance, however, and they landed on the chicken only $44.4 \%$ of the time. This population contributed to a statistically significant variation in host landing rates among AG populations (d.f. $=4, \chi^{2}=36.803, p<0.0001$ ).

\subsubsection{Multi-Day Host Switching by Individual Females}

The percentages of females that alternated hosts at least once during the multi-day assessment differed significantly by population (d.f. $=7, \chi 2=32.087, p<0.0001$ ). In the three human-seeking BG populations, the percentages of females landing on both the chicken and human host over the three day testing period were $21.6 \%, 30.0 \%$, and $45.2 \%$ for BG1, BG3, and BG2, respectively. In the four avian-seeking AG populations (AG1-AG4), a lower percentage of females alternated hosts: $24.4 \%, 5.6 \%, 12.5 \%$, and $0.0 \%$, respectively. Females from NY (AG5), which previously showed indiscriminate host landing behaviors (Figure 1B), had the highest percentage of females to switch hosts across test days, at $51.4 \%$. 


\subsection{Read Quality and Sample Clustering}

Sequencing of avian-seeking AG2 females and human-seeking BG1 females produced a total of 360,448,777 PE Illumina raw reads, and of these, 314,987,901 (87.4\%) remained after filter-trimming. The filtered average per sample read count was 26,248,992 (s.e.m. $=310,695$; Table S5). The CpipJ2 official gene set available from VectorBase contained 19,793 genes, and $12,710(64.2 \%)$ could be detected in our dataset based on our filtering criteria of 10 mapped reads per gene in at least four samples. A PCA of the expression profiles at these 12,710 genes confirmed that variation was greater between treatment groups than within (Figure 2). BG1 samples always clustered separately from AG2 samples along PC1, which explained $43.5 \%$ of the overall variation in the gene expression profiles for our dataset. Gravid (BG1 gravid) and host-seeking (BG1 parous and AG2) samples clustered separately on $\mathrm{PC} 2$, which explained $17.9 \%$ of the variation in our dataset. The relationships between PC1 and population as well as between PC2 and physiological state were supported by Bayesian generalized linear model coefficients, whose $95 \%$ credible intervals did not overlap with zero (Table S6). Spearman's Rank correlation coefficients calculated for pairs of samples further supported our PCA and indicated that gene expression profiles were more highly correlated within treatment (Figure S1).

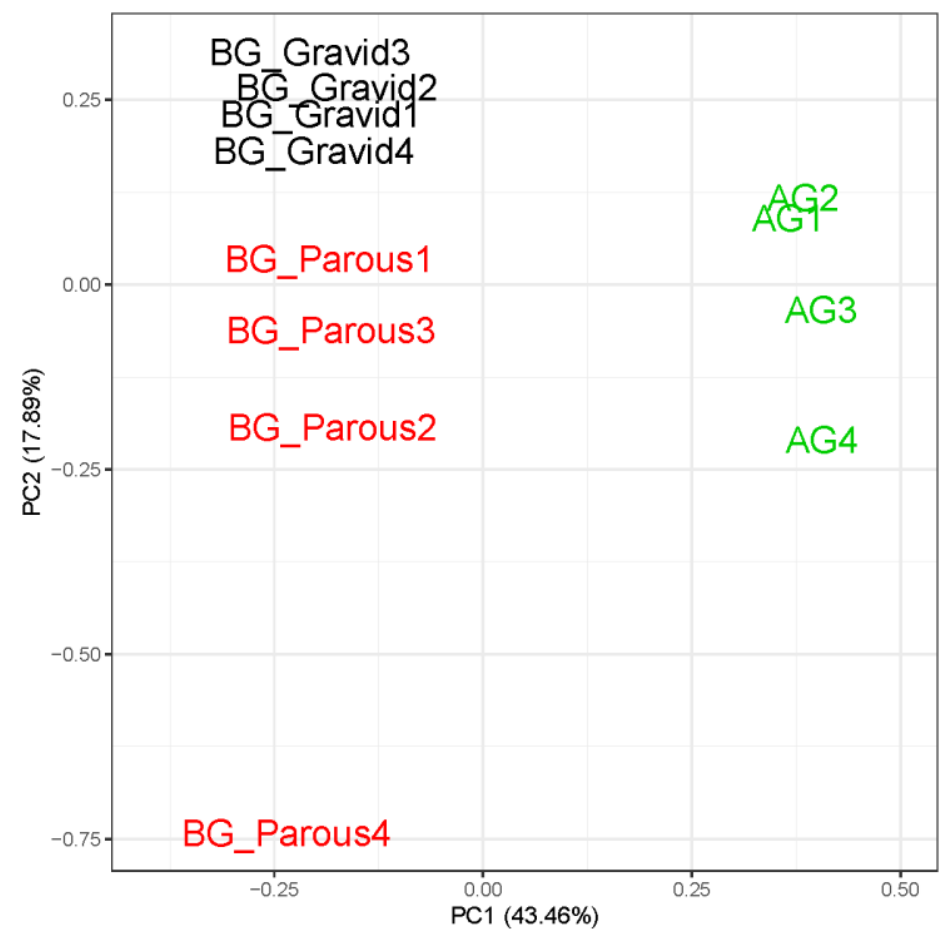

Figure 2. Principal component analysis (PCA) of sample-to-sample variation in gene expression profile at 12,710 genes for below-ground females (BG1) that are parous and gravid as well as aboveground females (AG2) that are nulliparous.

\subsection{Differential Gene Expression in the Heads of Behaviorally Divergent Females}

The numbers of statistically significant differentially expressed genes (DEGs) were 544 for the BG1 gravid vs. parous comparison, 2832 for the BG1 parous vs. AG2 nulliparous comparison, and 3011 for the BG1 gravid vs. AG2 nulliparous treatment comparison. When we applied an additional FC threshold (FC > 1.5), the number of DEGs dropped to $\mathrm{n}=16, \mathrm{n}=1394$, and $\mathrm{n}=1402$, respectively (Figure 3; see Data S1 for the full list of DEGs). The number of up- and down-regulated DEGs were similar within each treatment contrast, with no strong biases toward up or down regulation in any contrast (Table 2). 
A

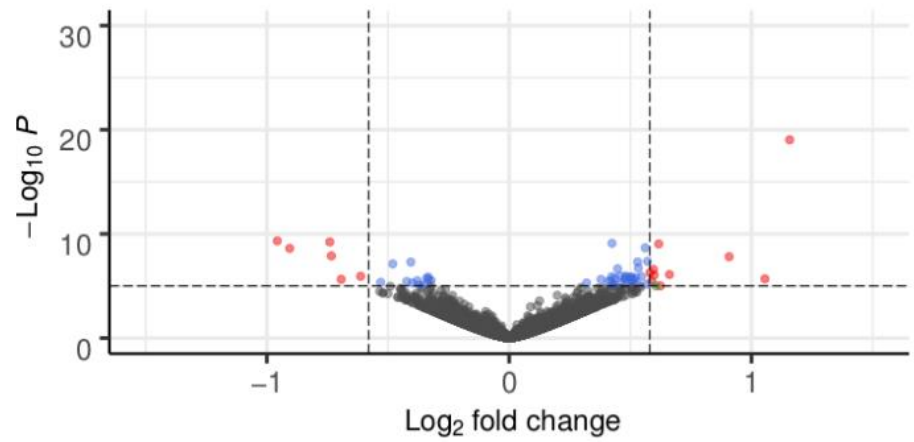

B

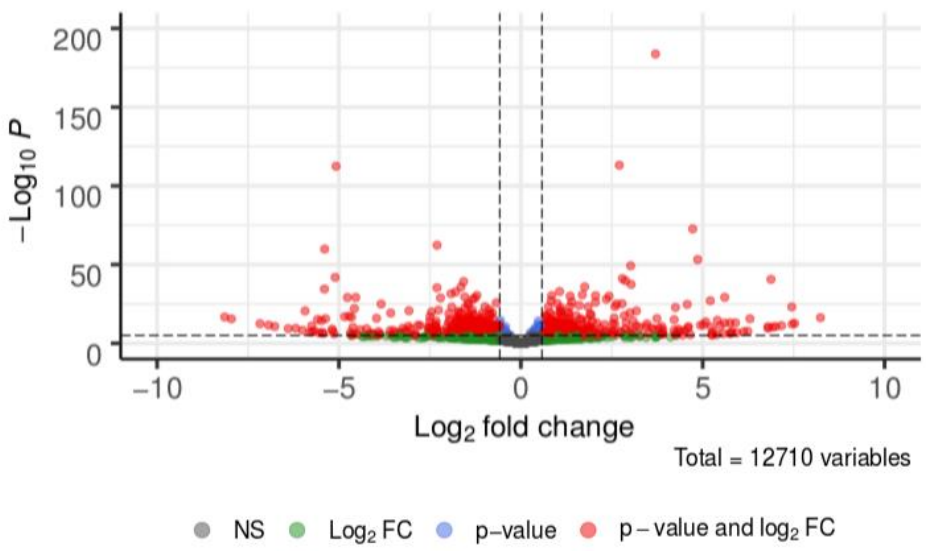

Figure 3. Differential gene expression (DGE) of 12,710 genes in the heads of below-ground Culex pipiens (BG1) and above-ground Cx. pipiens (AG2). Panel (A) shows DGE in a contrast between gravid and parous BG1 females. Panel (B) shows the contrast between parous BG1 and nulliparous AG2 females, both ready to engage in host-seeking behavior. Each point represents differential expression of a single gene, where grey points indicate no significant differences in expression, green points show $\log _{2}$ fold-change values that are not statistically significant, blue points represent genes with statistically significant differences in expression but low $\log _{2}$ fold-change values, and red points represent genes with a $>1.5$-fold difference between treatments where this difference was statistically significant.

Table 2. Numbers of differentially expressed genes that reach our fold change $( \pm 1.5)$ and statistical significance thresholds $(\alpha=0.05)$ after a Benjamini and Hochberg adjustment for false discovery rate. The reference for each treatment contrast is italicized.

\begin{tabular}{cccc}
\hline & $\begin{array}{c}\text { BG Gravid vs. } \\
\text { BG Parous }\end{array}$ & $\begin{array}{c}\text { BG Parous vs. } \\
\text { AG Nulliparous }\end{array}$ & $\begin{array}{c}\text { BG Gravid vs. } \\
\text { AG Nulliparous }\end{array}$ \\
\hline FC $>1.5$ (up) & 10 & 705 & 761 \\
FC $<1.5$ (down) & 6 & 689 & 641 \\
Total & 16 & 1394 & 1402 \\
\hline
\end{tabular}

Overlap and uniqueness of DGE patterns among the three contrasts indicated which DEGs were population-specific, or specific to physiological state (gravid versus hostseeking). A total of 453 genes were consistently upregulated and 457 genes were downregulated in AG2 females relative to BG1 females, regardless of their physiological state, consistent with population-specific differences in gene expression. Of these, only 253 genes were upregulated and 231 were downregulated in AG2 females relative to BG1 parous females in a physiological state compatible with host-seeking (Figure S2). Three genes were consistently downregulated and two consistently upregulated in BG1 gravid females rela- 
tive to both AG2 and BG1 parous host-seeking females, suggesting they play an important role in regulating behaviors of mosquitoes in gravid versus host-seeking states (Figure S2).

GO-slim enrichment analysis of the 16 DEGs for the BG1 gravid vs. parous contrast did not identify statistically significant over-representation of any functional gene set. This small number of DEGs included a uricase (CPIJ003456), a xanthine dehydrogenase (CPIJ004365), 4-hydroxyphenylpyruvate dioxygenase (CPIJ004417), a threonine dehydrogenase (CPIJ008256), an allantoicase (CPIJ012990), and an aminomethyltransferase (CPIJ014981), all of which were downregulated in BG1 gravid females. Upregulated genes in BG1 gravid females included E3 ubiquitin-protein ligase highwire (CPIJ003142), numb (CPIJ004690), a dual specificity protein phosphatase (CPIJ008018), a camp-specific 3,5-cyclic phosphodiesterase (CPIJ008747), heat shock protein 83 (CPIJ011244), cabut (CPIJ015908), and mitochondrial protein MAS5 (CPIJ018848). The strongest difference in gene expression occurred at cabut, whose expression was ca. two-fold higher in gravid BG1 females. Yet DEGs from our contrast of host-seeking BG1 parous to AG2 females were significantly enriched for those involved in sensory perception of chemical stimulus (GO:0007606; padj $=0.0197$ ), sensory perception $(G O: 0007600$; padj $=0.0202)$, and small molecule catabolic processes (GO:0044282; padj $=0.0479$ ). Because we were interested in identifying genes associated with mosquito responses to vertebrate hosts, further analyses of DEGs focused on families known to be associated with perception of visual cues and chemical volatiles.

\subsection{Splice Site Variation}

On average, STAR detected 5,758,457 ( $\pm 97,722$ s.e.m.), 5,844,577 ( $\pm 150,889$ s.e.m.), and 5,607,207 ( \pm 37,538 s.e.m.) total splice junctions for BG1 gravid, BG1 parous, and AG2 females, respectively. A modestly higher and more variable number of reads mapped uniquely for BG1 relative to AG2 females (Table S5), which had the potential to explain the higher mean and standard error for the numbers of splice junctions in BG1 treatments. When we divided the numbers of splice junctions by uniquely mapped reads, however, AG2 had a higher mean number of splice junctions per uniquely mapped read: 0.346 ( \pm 0.003 s.e.m.) as compared to 0.336 ( \pm 0.004 s.e.m.) and 0.345 ( \pm 0.002 s.e.m.) in BG1 parous and gravid treatments, respectively. Filtering STAR-detected junctions for uniqueness by population and treatment as well as on strandedness and average normalized read count ( $>100$ per gene) dramatically reduced the number of population- and treatment-specific splice junctions. We examined two pairwise comparisons: BG1 gravid vs. parous, and BG1 parous vs. AG2. For the first comparison, we identified 28 BG1 gravidspecific splice junctions found in 26 genes, and two BG1 parous-specific splice junctions in two genes. A Chi-square test $(\chi 2=20.6, p<0.0001)$ showed that BG1 gravid females had greater splice site variation than did parous females. For the second comparison, 27 BG1 parous specific splice junctions were found in 26 genes, and 98 AG2 specific splice junctions were found in 94 genes. A Chi-square test $(\chi 2=38.8, p<0.0001)$ indicated that AG2 females had greater splice site variation than did BG1 parous females. A full list of population-specific splice junctions can be found in Data S2. Most of these did not occur at genes with evidence of DGE. For the BG1 gravid vs. parous, no splice variation was observed at any DEG. For the BG1 parous vs. AG2 comparison, however, splice variants were detected at two DEGs in BG1 parous females and at 18 DEGs in AG2 females (Table S7).

\subsection{Candidate Sensory Gene Analysis}

In total, our filtered RNA-seq dataset contained 10 OR, 10 IR, 10 GR, 42 OBP, 2 SNMP, and 11 CSP genes as well as eight opsin genes. Of these, many were differentially expressed according to the adjusted $p$-value, although fewer had 1.5-fold greater or lower expression in AG2 relative to BG1 parous females (Table 3). One OR orthologous to $C x$. quinquefasciatus OR137, one unnamed GR, and SNMP1a were all downregulated in AG2 females. In contrast, all differentially expressed CSPs were upregulated in AG2 females, where the increase in CSP4 expression was $<1.5$-fold, increases in CSP2 and CSP23 expression were moderate 
(2.6- and 1.7-fold, respectively), and the increase in CSP13 expression was highest (26-fold). All of these genes shared significant protein sequence homology with genes from other mosquito species, according to OrthoMCL-db.

Table 3. Differentially expressed genes with sensory function in the whole heads of above-ground (AG2) host-seeking females relative to below-ground host-seeking females. $p$-values are adjusted for multiple comparisons using a BenjaminiHochberg false discovery rate correction. Bolded lines have both a statistically significant Benjamini-Hochberg adjusted $p$-value (padj) and an absolute $\log _{2}$ fold change (FC) value greater than 0.58 (equivalent to a 1.5-fold difference).

\begin{tabular}{|c|c|c|c|c|c|}
\hline Gene Family & Vector Base ID & Gene Name & $\log _{2}$ FC (Shrunken) & padj & Orthology Group \\
\hline Odorant receptor & CPIJ016433 & OR137 & -2.54 & $9.6 \times 10^{-5}$ & OG6_163622 \\
\hline Ionotropic receptor & CPIJ019300 & IR76b & 0.55 & $3.6 \times 10^{-3}$ & OG6_126385 \\
\hline Gustatory receptor & CPIJ011564 & NA & -1.22 & $2.4 \times 10^{-2}$ & OG6_187005 \\
\hline \multirow[t]{15}{*}{ Odorant Binding Proteins } & CPIJ001730 & ОВР4 & -1.07 & $4.0 \times 10^{-4}$ & OG6_201790 \\
\hline & CPIJ002108 & OBP108 & -0.83 & $4.0 \times 10^{-2}$ & OG6_136613 \\
\hline & CPIJ002109 & OBP107 & -1.11 & $1.1 \times 10^{-2}$ & OG6_151055 \\
\hline & CPIJ002111 & OBP110 & -0.60 & $2.6 \times 10^{-2}$ & OG6_163322 \\
\hline & CPIJ004145 & ОВР64 & -4.73 & $7.6 \times 10^{-16}$ & OG6_140589 \\
\hline & CPIJ004634 & OBP102 & 0.49 & $6.1 \times 10^{-3}$ & OG6_142050 \\
\hline & CPIJ007604 & OBP1 & -0.49 & $2.1 \times 10^{-2}$ & OG6_117872 \\
\hline & CPIJ007617 & OBP2 & -0.65 & $6.4 \times 10^{-3}$ & OG6_163124 \\
\hline & CPIJ008793 & OBP6 & -0.55 & $2.0 \times 10^{-4}$ & OG6_110106 \\
\hline & CPIJ009568 & OBP8 & 0.64 & $1.4 \times 10^{-4}$ & OG6_110106 \\
\hline & CPIJ010367 & ОВР55 & -1.09 & $1.0 \times 10^{-12}$ & OG6_124323 \\
\hline & CPIJ010787 & ОВР51 & 2.30 & $9.1 \times 10^{-11}$ & OG6_150797 \\
\hline & CPIJ012716 & OBP17 & 0.89 & $2.1 \times 10^{-2}$ & OG6_107904 \\
\hline & CPIJ012717 & OBP18 & 1.07 & $2.4 \times 10^{-2}$ & OG6_150726 \\
\hline & CPIJ012719 & ОВР20 & 3.18 & $5.4 \times 10^{-19}$ & OG6_107904 \\
\hline \multirow[t]{6}{*}{ Odorant Binding Proteins } & CPIJ013976 & OBP10 & 8.24 & $6.2 \times 10^{-15}$ & OG6_153567 \\
\hline & CPIJ014525 & OBP24 & 0.64 & $8.9 \times 10^{-4}$ & OG6_107904 \\
\hline & CPIJ016479 & ОВР32 & -0.77 & $3.8 \times 10^{-2}$ & OG6_117689 \\
\hline & CPIJ016965 & OBP28 & 0.46 & $5.5 \times 10^{-3}$ & OG6_128903 \\
\hline & CPIJ016966 & ОВР29 & -1.92 & $2.0 \times 10^{-29}$ & OG6_128903 \\
\hline & CPIJ019610 & OBP36 & -0.81 & $1.2 \times 10^{-2}$ & OG6_167102 \\
\hline Sensory Neuron Membrane Protein & CPIJ014330 & SNMP1a & -0.62 & $5.0 \times 10^{-3}$ & OG6_117830 \\
\hline \multirow[t]{4}{*}{ Chemosensory Proteins } & CPIJ002605 & CSP2 & 1.42 & $1.9 \times 10^{-12}$ & OG6_120812 \\
\hline & CPIJ002608 & CSP4 & 0.32 & $4.9 \times 10^{-2}$ & OG6_107706 \\
\hline & CPIJ002618 & CSP13 & 4.66 & $6.3 \times 10^{-5}$ & OG6_120813 \\
\hline & CPIJ002628 & CSP23 & 0.78 & $7.3 \times 10^{-6}$ & OG6_162766 \\
\hline \multirow[t]{6}{*}{ Opsins } & CPIJ004067 & GPROP1 & -0.60 & $1.3 \times 10^{-3}$ & OG6_163080 \\
\hline & CPIJ005000 & GPROP2 & 0.24 & $3.1 \times 10^{-2}$ & OG6_120825 \\
\hline & CPIJ009246 & GPROP3 & 0.19 & $4.5 \times 10^{-2}$ & OG6_124296 \\
\hline & CPIJ011571 & GPROP6 & 0.50 & $9.2 \times 10^{-8}$ & OG6_104608 \\
\hline & CPIJ011573 & GPROP7 & 0.54 & $4.7 \times 10^{-3}$ & OG6_104608 \\
\hline & CPIJ014334 & GPROP12 & 0.48 & $3.0 \times 10^{-2}$ & OG6_105417 \\
\hline
\end{tabular}

Twenty-two of the 42 OBPs detected in our dataset were differentially expressed, and 18 of them had at least a 1.5-fold difference in expression between host-seeking BG1 parous and AG2 females (Table 3). Twelve were downregulated in AG2 females, 10 of which showed at least 1.5-fold lower expression. The remaining 10 OBPs were upregulated in AG2 females, where eight had at least 1.5-fold higher expression. The greatest expression difference occurred at OBP10, where expression was detected in all AG2 samples but never detected in BG1 parous females. Seventeen of these 22 differentially expressed Culex OBPs shared significant protein sequence homology with OBPs from other mosquito species, while five were found only in Culex.

We detected eight opsin genes in our DGE dataset: four long-wave sensitive opsins (GPROPS 1, 5, 6, 7), one short wave sensitive opsin (GPROP2), one UV detecting opsin (GPROP3), a pteropsin ortholog (GPROP12), and an ortholog of the conserved Rh7 (GPROP4). Statistically significant differences in expression-level were detected at seven of these opsins when we compared AG2 and parous BG1 females. All opsin genes not only shared significant protein sequence homology with those from other mosquito species, but also with insects from other families. 
Six sensory genes from Table 3 were selected for qPCR validation of our DGE results (Table S8). Of these, OBP10, CSP2, CSP4, and GPROP12 were found to be more highly expressed in the avian-seeking AG1 population, while OBP2 was more highly expressed in the human-seeking BG1 population. These results agreed with fold change trends observed in our DGE analysis, with a single exception, GPROP1 (Table S9).

\section{Discussion}

We observed significant variation in host responses among North American $C x$. pipiens collected from above- and below-ground sites, as has been described for other mosquito species [1]. All BG populations showed consistent day one overall response rates $(>50.0 \%)$ and a higher, albeit significantly variable percentage of landings on the human host (69.2-85.4\%). BG1 females had the highest rates of human landing, comparable to results from [23], when they were previously studied. Interestingly, BG2 females, which were derived from the same initial collection [37] but were reared separately and never offered a blood meal, had lower overall host response rates than BG1 and the lowest human landing rates $(69.2 \%)$ of all three BG populations. While it is possible that the initial split of BG1 from BG2 resulted in an uneven allocation of "human-seeking" alleles to the founders $\mathrm{BG} 1$, these differences could also be due to the unique rearing regimes experienced by these populations in the years following their split.

Among AG populations, there was significant variation in both day one overall response rates (range $=28.0-75.8 \%$ ) and human landing rates (range $=9.1-55.6 \%$ ). The population from Laurel, MD (AG4), had the lowest day one response rates, while AG5 from New York City, NY, had the highest. AG1-3 populations collected from three different sites in metropolitan Chicago, IL, showed avian acceptance rates $>80 \%$. This agreed with previous blood meal analyses of field-collected AG Cx. pipiens from metropolitan Chicago showing that they are predominantly avian-feeding $[56,75,76]$. AG4 showed the strongest bias toward landing on the chicken $(90.9 \%)$, yet was not significantly different from AG1-AG3. Less than one quarter of the tested females from AG1-AG4 switched hosts during multi-day testing. Yet AG5 from NY, which showed no strong patterns of landing on either the avian or human host, frequently alternated hosts over multiple days of testing. It is unclear whether behavioral differences observed for AG5 relative to other AG populations were related to differences in their previous rearing regime or natural genetic variation that existed between populations prior to collection. Previous blood meal analyses of $C x$. pipiens from the Borough of Queens in New York City showed little evidence of mammal feeding [47]. But avian-preferring AG1 and opportunistic AG5 were both established by the CDC in Fort Collins, CO, and reared under similar conditions both there and in our hands. The source of variation in host preference for AG5 relative to other AG populations remains unresolved, but such within-species variation has been observed for other mosquito taxa [1].

Previous work has indicated a genetic basis for mosquito host preference [15,74-79], including for $C x$. pipiens [23]. Therefore, we used RNA sequencing as a first step toward quantifying gene expression differences and splice site variation for one avian- (AG2) and one human-seeking (BG1) population of $C x$. pipiens. Furthermore, we examined gene expression changes and splice site variation that occur in facultatively autogenous females (BG1) as they transition from a gravid to a parous host-seeking state. Our initial comparison of BG1 gravid versus parous females identified several hundred genes with statistically significant differences in expression, but only 16 with greater than 1.5-FC. Of these 16, five were consistently up- or down-regulated in gravid females relative to host-seeking females of both BG1 and AG2, suggesting that they may regulate blood feeding behaviors or physiological preparedness for blood meal digestion. We also identified splice site variation that appeared to be specific to gravid and parous physiological states in BG1. Twenty-six genes expressed by gravid females contained unique splice junctions not found in parous females. In comparison, only two genes expressed by parous females contained splice junctions not found in gravid females. This raises the intriguing possibility that 
alternative splicing may play a role in inhibition of blood feeding behaviors while females are gravid. None of the 16 differentially expressed genes described above contained splice junctions unique to gravid or parous females, however.

Differentially expressed genes in the comparison of BG1 gravid and parous females included a uricase (CPIJ003456), 4-hydroxyphenylpyruvate dioxygenase (CPIJ004417), and a threonine dehydrogenase (CPIJ008256), which were downregulated in gravid females, as well as cabut (CPIJ015908) and mitochondrial protein MAS5 (CPIJ018848), which were upregulated in gravid females. Free amino acid metabolism and excretion of the nitrogenous waste are critical physiological processes for blood feeding insects. In a close relative, $C x$. pipiens pallens, free amino acid concentrations are detected in the hemolymph of blood feeding females as quickly as four hours post-blood-meal [80]. Perhaps the expression of 4-hydroxyphenylpyruvate dioxygenase and threonine dehydrogenase, which are critical to phenylalanine/tyrosine [81] and threonine [82] metabolism, respectively, increases in host-seeking females relative to gravid females in preparation for a blood meal and the subsequent amino acid metabolism. Likewise, uricase, which plays a critical role in the degradation of uric acid during and after a blood meal [83], was also higher in host-seeking females. Upregulation of all three genes has even been detected in chemosensory tissues $[84,85]$. Interestingly, both xanthine dehydrogenase and allantoicase, with metabolic and excretory functions, respectively $[83,86]$, were both more highly expressed in hostseeking BG1 parous females as compared to BG1 gravid females. Yet expression of these genes was lower in AG2 females than in BG1 gravid females. Perhaps there are formspecific interactions with the physiological state that can explain the different expression patterns of these latter two genes.

Upregulation of the transcription factor cabut (CPIJ015908) by females in a gravid state was also of interest due to its involvement in diverse physiological and developmental processes. In Drosophila melanogaster, cabut is involved in growth control, sugar metabolism, and regulation of the circadian clock [87]. It is inducible by 20-hydroxyecdsone (20E) during metamorphosis [88] as well as by sugar-feeding, when both cabut and a second transcription factor, sugarbabe, are strongly upregulated by Mondo-Mlx [87]. In our Cx. pipiens, there was no indication that sugar-feeding was the cause of the differences in the expression of cabut; sugarbabe (CPIJ007837) expression patterns did not correspond to cabut expression patterns among our treatments. Instead, it is known that ovarian ecdysteroidogenic hormone $(\mathrm{OEH})$ production following a blood meal triggers the ovaries of female mosquitoes to produce 20E [89,90]. Furthermore, in the facultatively autogenous mosquito, Georgecraigius atropalpus, $\mathrm{OEH}$ is expressed after adult emergence and triggers the 20E hormonal cascade without a blood meal [91]. Perhaps the 20E hormonal cascade that occurs PE in our facultatively autogenous BG1 population triggers the expression of cabut. Future work should be directed at the consequences of cabut expression for blood feeding and the reproductive behaviors of this vector species.

When we compared gene expression profiles for human-seeking BG1 and avianseeking AG2, both in a physiological state compatible with host-seeking, we identified 1394 genes with statistically significant differences in expression and with a FC of at least 1.5. It is possible that greater FCs and more differentially expressed genes would have been detected had females been used directly from the behavioral assay after landing on human and avian hosts, rather than simply pooling by population. Further studies could confirm this. Along with expression level differences, we also detected splice site variation at dozens of expressed, annotated genes in this pair of populations (Data S2). While gene up- and down-regulation did not appear to strongly differ for human-seeking BG1 and avian-seeking AG2 (Table 2), splice site variants did. AG2 had three times more population-specific splice variants (98 in 94 unique genes) than did BG1 parous females (27 in 26 unique genes). Read counts in AG2 were slightly lower than for BG1 (Table S5), ruling out the possibility that more AG2 variants were detected as a result of deeper sequencing. Instead, there may be greater genetic variation in our AG populations relative 
to BG1, giving rise to more alternative splice sites. This is consistent with previous studies of genetic variation in these populations [30].

Given the importance of volatile cues to host detection [17], we specifically examined whether any chemosensory genes were differentially expressed in this pair of populations. Cx. quinquefasciatus has a chemosensory suite consisting of 180 ORs, 73 IRS, 69 GRs, 109 OBPs, 2 SNMPs, and 27 CSPs, and we expected $C x$. pipiens to have similar numbers based on their close evolutionary relationship with $C x$. quinquefasciatus. In our dataset, we were able to detect a portion of these genes: 10 ORs, 10 IRs, 10 GRs, 42 OBPs, 2 SNMPs, and 11 CSPs. This was due to our sequencing strategy. Targeting the whole heads of these behaviorally divergent populations, which bore both the chemosensory appendages and compound eyes, allowed us to quantify differences in expression of genes involved in vision. We identified several opsins that were significantly but modestly upregulated $(G P R O P 2,3,6,7,12)$ in our avian-seeking population, and the differential expression of one of these genes, GPROP12, was confirmed by qPCR. For this family, it is possible that differences in lifestyle (above- vs. below-ground) have selected for the observed differences in gene expression, but future work is needed to demonstrate what role, if any, these genes play in behavioral differences between above- and below-ground $C x$. pipiens.

Sequencing of whole heads to include compound eyes was carried out at the expense of sensitivity for lowly expressed chemosensory genes. Yet even at this coarse resolution, we detected statistically significant differences in expression at dozens of chemosensory genes (Table 3). As one example, OR137, which has the potential for involvement in Cx. quinquefasciatus host-seeking behaviors due to its antennal expression [92] as well as downregulation following a blood meal [85], was strongly downregulated in our avianseeking females relative to human-seeking females. An unnamed GR (CPIJ011564) was also significantly downregulated in our avian-seeking AG2 population, but its tissue specificity and expression patterns pre- and post-blood meal are not known. IR76b, which is expressed in the antennae of Cx. quinquefasciatus [84] and whose homologue in Anopheles gambiae responds to butylamine [88], was modestly upregulated in our avian-seeking $C x$. pipiens. Avian-seeking $C x$. quinquefasciatus respond to this volatile compound in single sensillum recordings [93], so perhaps higher levels of IR76b expression in our avian-seeking $C x$. pipiens are part of the mechanism by which they detect their preferred host.

Proportionally, divergence in OBP and CSP expression levels comprised the majority of the chemosensory gene expression differences in our comparison of AG2 and BG1 parous females. Previous studies have shown that genes involved in odorant binding, including OBPs, are among the most rapidly evolving for the above- and below-ground Cx. pipiens forms [94]. The roles of these gene families in host detection remain unclear in mosquitoes $[17,95]$, but OBPs are known to influence host preference in phytophagous insect species [96]. This makes the observed differences in expression levels between our human- and avian-seeking populations of particular interest. While the CSP genes detected in our dataset always had homologues in other vector species, several of our OBPs did not (OBP4, OBP10, OBP32, OBP36, and OBP64). Indeed, some of the strongest expression level differences we saw in the candidate sensory genes were from CSP and OBP gene families, including several OBPs that were Culex specific. OBP10, OBP20, OBP51, and CSP13 had more than four-fold higher expression in our avian-seeking $C x$. pipiens. OBP64, on the other hand, was strongly downregulated in the avian-seeking population. Of these, OBP10 and OBP51 are expressed in the antennae of $C x$. quinquefasciatus, while OBP20 and OBP64 can be detected in other tissues [84]. This lack of antennal specificity does not necessarily preclude a role in host detection [96], and future studies should investigate whether changes in expression levels of these genes impact host preference in $C x$. pipiens.

Three genes relevant to host detection and feeding, but not included in our candidate sensory gene analysis, were also differentially expressed in our human- and avianseeking Cx. pipiens: acj6 (CPIJ014571), a pickpocket gene (ppk; CPIJ007315), and a d7 long form salivary gland protein (CPIJ014550). The transcription factor acj6 was previously shown to determine the odor specificities of a subset of olfactory receptor neurons in $D$. 
melanogaster [97], and this gene was moderately but significantly upregulated in the heads of our avian-seeking $C x$. pipiens. Perhaps the observed differences in expression levels of this transcription factor impact the patterning and expression of receptors on ORNs in our human- and avian-seeking mosquito populations. Work in D. melanogaster has also shown that members of the pickpocket family of epithelial sodium channels are involved in the taste system [98], and one unnamed ppk was strongly downregulated in our avian-seeking population. Finally, while not necessarily involved in host detection, d7 long form salivary gland proteins are important to mammal feeding in $C x$. quinquefasciatus [99]. One such protein was significantly upregulated in avian-seeking females, although it was not the homolog of ADP-binding CxD7L1, known to enhance mammal feeding. We speculate that the $p p k$ and salivary gland proteins may play a role in the final stages of host acceptance post-landing and perhaps facilitate feeding in our behaviorally divergent populations, although we have not yet studied what, if any, behavioral differences exist between our $C x$. pipiens populations after landing.

\section{Conclusions}

Cx. pipiens is a bridge vector of WNV in North America [75], where avian-seeking behaviors contribute to viral amplification in avian species, and mammal-seeking behavior drives epizootic transmission of the virus into humans. Here we quantified the extent of variation in host preference for $C x$. pipiens collected from AG and BG breeding and overwintering sites. We identified host landing patterns ranging from highly avian-seeking, which was most typical in AG populations, to human-seeking, which was primarily observed in BG populations. Pairwise comparisons of gene expression from the heads of human-preferring females in gravid and host-seeking states as well as the comparison of human- and avian-seeking females resulted in identification of DEGs with metabolic, chemosensory, vision, and regulatory function. Future functional work will determine the specific roles of these genes in our behaviorally divergent populations.

Supplementary Materials: The following are available online at https:/ /www.mdpi.com/2075-4 $450 / 12 / 3 / 271 / s 1$, Supplemental Methods describe the analysis of BG1 at two and three weeks PE, mosquito rearing methods prior to RNA sequencing, and qPCR validation of sensory genes. Table S1 shows collection information for each of the eight tested $C x$. pipiens populations. Table S2 provides means and $95 \%$ CIs for overall response rates, human acceptance rates, and rates of host switching for all eight $C x$. pipiens populations. Table S3 shows RNA quality indicators and Illumina indices used for sequencing. Table S4 shows the results of BG1 behavioral analyses at different PE times. Table S5 contains filtering and alignment statistics for our RNA-seq experiment. Table S6 contains the analysis of PCs 1 and 2 with respect to mosquito population and physiological state. Table S7 shows DEGs with population-specific splice variants. Table S8 contains qPCR primer sequences used for sensory gene expression validation. Table S9 provides qPCR validation results for six selected genes from Table S3. Figure S1 contains Spearman's rank correlation coefficients for paired sample gene expression profiles. Figure S2 contains a Venn diagram of the numbers of differentially expressed genes for each pairwise comparison. Data S1 contains all differentially expressed genes according to adjusted $p$-value for all pairwise RNA-seq treatment comparisons. Data S2 contains splice junctions unique to each sequenced population.

Author Contributions: A.N. conducted the behavioral experiments as well as collected tissue and isolated RNA for sequencing experiments. A.N. and M.L.F. designed the experiments, analyzed the data, and prepared the manuscript for publication. Both authors have read and agreed to the published version of the manuscript.

Funding: Funding for this work was provided by the University of Maryland Brain and Behavior Initiative and the National Institutes of Health R01AI125622A to M.L.F.

Institutional Review Board Statement: The use of animal subjects was approved by the University of Maryland Institutional Animal Use and Care Committee under protocol number 1094335. 
Data Availability Statement: RNA-seq data have been archived at NCBI BioProject accession PRJNA702543 (https:/ / www.ncbi.nlm.nih.gov/sra/PRJNA702543, accessed on 15 March 2021). Behavioral data and all scripts used for data analysis are available at https:/ / github.com/mcadamme/ Culex_RNAseq_Chemosensory/(accessed on 15 March 2021).

Acknowledgments: Roger Nasci and Linda Kothera provided mosquito cultures used in behavioral experiments. The authors thank Carlos Machado for assistance with RNA isolation and quality control. We also thank Alys Jarvela and Katie Reding for assistance with qPCR primer and assay design.

Conflicts of Interest: The authors declare they have no conflict of interest.

\section{References}

1. Takken, W.; Verhulst, N. Host preferences of blood-feeding mosquitoes. Annu. Rev. Entomol. 2013, 58, 433-453. [CrossRef] [PubMed]

2. Garrett-Jones, C. Prognosis for interruption of malaria transmission through assessment of the mosquito's vectorial capacity. Nature 1964, 204, 1173-1175. [CrossRef] [PubMed]

3. Friend, W.G.; Smith, J.J.B. Factors affecting feeding by bloodsucking insects. Annu. Rev. Entomol. 1997, 22, 309-331. [CrossRef]

4. Bowen, M.F. The sensory physiology of host-seeking behavior in mosquitoes. Annu. Rev. Entomol. 1991, 36, 139-158. [CrossRef]

5. van Breugel, F.; Riffell, J.; Fairhall, A.; Dickinson, M.H. Mosquitoes use vision to associate odor plumes with thermal targets. Curr. Biol. 2015, 25, 2123-2129. [CrossRef]

6. Cardé, R.T. Multi-cue integration: How female mosquitoes locate a human host. Curr. Biol. 2015, 25, R793-R795. [CrossRef]

7. Kennedy, J.S. The visual responses of flying mosquitoes. Proc. Zool. Soc. 1940, 109, 221-242. [CrossRef]

8. Reeves, W.C. Field Studies on Carbon Dioxide as a Possible Host Simulant to Mosquitoes. Proc. Soc. Exp. Biol. Med. 1951, 77, 64-66. [CrossRef]

9. Gillies, M.T. The role of carbon dioxide in host-finding by mosquitoes (Diptera: Culicidae): A review. Bull. Entomol. Res. 1980, 70, 525-532. [CrossRef]

10. Smallegange, R.C.; Schmied, W.H.; van Roey, K.J.; Verhulst, N.O.; Spitzen, J.; Mukabana, W.R.; Takken, W. Sugar-fermenting yeast as an organic source of carbon dioxide to attract the malaria mosquito Anopheles gambiae. Malar. J. 2010, 9, 292. [CrossRef]

11. McMeniman, C.J.; Corfas, R.A.; Matthews, B.J.; Ritchie, S.A.; Vosshall, L.B. Multimodal integration of carbon dioxide and other sensory cues drives mosquito attraction to humans. Cell 2014, 156, 1060-1071. [CrossRef]

12. Hawkes, F.; Gibson, G. Seeing is believing: The nocturnal malarial mosquito Anopheles coluzzii responds to visual host-cues when odour indicates a host is nearby. Parasit Vectors 2016, 9, 320. [CrossRef]

13. Dekker, T.; Cardé, R.T. Moment-to-moment flight manoeuvres of the female yellow fever mosquito (Aedes aegypti L.) in response to plumes of carbon dioxide and human skin odour. J. Exp. Biol. 2011, 214, 3480-3494. [CrossRef]

14. Takken, W.; Knols, B.G.J.; Otten, H. Interactions between physical and olfactory cues in the host-seeking behaviour of mosquitoes: The role of relative humidity. Ann. Trop. Med. Parasit. 1997, 91 (Suppl. 1), S119-S120. [CrossRef]

15. DeGennaro, M.; McBride, C.S.; Seeholzer, L.; Nakagawa, T.; Dennis, E.J.; Goldman, C.; Jasinskiene, N.; James, A.A.; Vosshall, M.B. orco mutant mosquitoes lose strong preference for humans and are not repelled by volatile DEET. Nature 2013, 498, 487-491. [CrossRef]

16. Suh, E.; Bohbot, J.D.; Zweibel, L.J. Peripheral olfactory signaling in insects. Curr. Opin. Insect. Sci. 2014, 6, 86-92. [CrossRef] [PubMed]

17. Montell, C.; Zwiebel, L.J. Mosquito Sensory Systems. In Advances in Insect Physiology; Academic Press: Cambridge, MA, USA, 2016; Volume 51, pp. 293-328.

18. Corfas, A.; Vosshall, L. The cation channel TRPA1 tunes mosquito thermotaxis to host temperatures. Elife 2015, 4, e11750. [CrossRef]

19. Zwiebel, L.J.; Takken, W. Olfactory regulation of mosquito-host interactions. Insect Biochem. Mol. 2004, 34, 645-652. [CrossRef]

20. Pelletier, J.; Leal, W.S. Genome analysis and expression patterns of odorant-binding proteins from the Southern House mosquito Culex pipiens quinquefasciatus. PLoS ONE 2009, 4, e6237. [CrossRef]

21. Silbering, A.F.; Rytz, R.; Grosjean, Y.; Abuin, L.; Ramdya, P.; Jefferis, G.S.; Benton, R. Complementary function and integrated wiring of the evolutionarily distinct Drosophila olfactory subsystems. J. Neurosci. 2011, 31, 13357-13375. [CrossRef]

22. Harbach, R.E. Culex pipiens: Species versus species complex-taxonomic history and perspective. J. Am. Mosq. Control Assoc. 2012, 28, 10-23. [CrossRef]

23. Fritz, M.L.; Walker, E.D.; Miller, J.R.; Severson, D.W.; Dworkin, I. Divergent host preferences of above-and below-ground Culex pipiens mosquitoes and their hybrid offspring. Med. Vet. Entomol. 2015, 29, 115-123. [CrossRef]

24. Kilpatrick, M.; Daszak, P.; Jones, M.J.; Marra, P.P.; Kramer, L.D. Host heterogeneity dominates West Nile virus transmission. Proc. Royal. Soc. B 2006, 273, 2327-2333. [CrossRef] [PubMed]

25. Huang, S.; Molaei, G.; Andreadis, T.G. Genetic insights into the population structure of Culex pipiens (Diptera: Culicidae) in the northeastern United States by using microsatellite analysis. Am. J. Trop. Med. Hyg. 2008, 79, 518-527. [CrossRef] [PubMed] 
26. Rudolf, M.; Czajka, C.; Börstler, J.; Melaun, C.; Jöst, H.; von Thien, H.; Badusche, M.; Becker, N.; Schmidt-Chanasit, J.; Kruger, A.; et al. First nationwide surveillance of Culex pipiens complex and Culex torrentium mosquitoes demonstrated the presence of $C u l e x$ pipiens biotype pipiens/molestus hybrids in Germany. PLoS ONE 2013, 8, e71832. [CrossRef]

27. Fonseca, D.M.; Keyghobadi, N.; Malcolm, C.A.; Mehmet, C.; Schaffner, F.; Mogi, M.; Fleischer, R.; Wilkerson, R.C. Emerging vectors in the Culex pipiens complex. Science 2004, 303, 1535-1538. [CrossRef]

28. Farajollahi, A.; Fonseca, D.M.; Kramer, L.D.; Kilpatrick, A.M. "Bird biting” mosquitoes and human disease: A review of the role of Culex pipiens complex mosquitoes in epidemiology. Infect. Genet. Evol. 2011, 11, 1577-1585. [CrossRef] [PubMed]

29. Gomes, B.; Sousa, C.A.; Vicente, J.L.; Pinho, L.; Calderón, I.; Arez, E.; Almeida, A.; Donnelly, M.J.; Pinto, J. Feeding patterns of molestus and pipiens forms of Culex pipiens (Diptera: Culicidae) in a region of high hybridization. Parasit Vectors $2013,6,93$. [CrossRef]

30. Yurchenko, A.A.; Masri, R.A.; Khrabrova, N.V.; Sibataev, A.K.; Fritz, M.L.; Sharakhova, M.V. Genomic differentiation and intercontinental population structure of mosquito vectors Culex pipiens pipiens and Culex pipiens molestus. Sci. Rep. 2020, 10, 1-13. [CrossRef]

31. Spielman, A.; Wong, J. Environmental control of ovarian diapause in Culex pipiens. Ann. Entomol. Soc. 1973, 66, 905-907. [CrossRef]

32. Vinogradova, E.B. Culex Pipiens Pipiens Mosquitoes: Taxonomy, Distribution, Ecology, Physiology, Genetics, Applied Importance and Control (No. 2); Pensoft Publishers: Sofia, Bulgaria, 2000.

33. Mori, A.; Romero-Severson, J.; Severson, D.W. Genetic basis for reproductive diapause is correlated with life history traits within the Culex pipiens complex. Insect Mol. Biol. 2007, 16, 515-524. [CrossRef] [PubMed]

34. Sim, C.; Denlinger, D.L. Insulin signaling and FOXO regulate the overwintering diapause of the mosquito Culex Pipiens. Proc. Natl. Acad. Sci. USA 2008, 105, 6777-6781. [CrossRef]

35. Denlinger, D.L.; Armbruster, P.A. Mosquito diapause. Annu. Rev. Entomol. 2014, 59, 73-93. [CrossRef] [PubMed]

36. Byrne, K.; Nichols, R.A. Culex pipiens in London Underground tunnels: Differentiation between surface and subterranean populations. Heredity 1999, 82, 7-15. [CrossRef]

37. Mutebi, J.P.; Savage, H.M. Discovery of Culex pipiens pipiens form molestus in Chicago. J. Am. Mosq. Control Assoc. 2009, 25, 500-503. [CrossRef]

38. Kothera, L.; Godsey, M.; Mutebi, J.P.; Savage, H.M. A Comparison of Aboveground and Belowground Populations of Culex pipiens (Diptera: Culicidae) Mosquitoes in Chicago, Illinois, and New York City, New York, Using Microsatellites. J. Med. Entomol. 2010, 47, 805-813. [CrossRef]

39. Becker, N.; Jöst, A.; Weitzel, T. The Culex pipiens complex in Europe. J. Am. Mosq. Control Assoc. 2012, 28, 53-67. [CrossRef]

40. Reisen, W.K. The contrasting bionomics of Culex mosquitoes in western North America. J. Am. Mosq. Control Assoc. 2012, 28, 82-91. [CrossRef]

41. Reusken, C.B.E.M.; De Vries, A.; Buijs, J.; Braks, M.A.H.; Den Hartog, W.; Scholte, E.J. First evidence for presence of Culex pipiens biotype molestus in the Netherlands, and of hybrid biotype pipiens and molestus in northern Europe. J. Vector Ecol. 2010, 35, 210-212. [CrossRef]

42. Kim, S.; Trocke, S.; Sim, C. Comparative studies of stenogamous behaviour in the mosquito Culex pipiens complex. Med. Vet. Entomol. 2018, 32, 427-435. [CrossRef]

43. Spielman, A. The inheritance of autogeny in the Culex pipiens complex of mosquitoes. Am. J. Hyg. 1957, 65, 404-425.

44. Spielman, A. Population structure in the Culex pipiens complex of mosquitos. Bull. World Health Organ. 1967, 37, 271.

45. Strickman, D.; Fonseca, D.M. Autogeny in Culex pipiens complex mosquitoes from the San Francisco Bay Area. Am. J. Trop. Med. Hyg. 2012, 87, 719-726. [CrossRef]

46. Gao, Q.; Su, F.; Zhou, Y.B.; Chu, W.; Cao, H.; Song, L.L.; Leng, P.E. Autogeny, Fecundity, and Other Life History Traits of Culex pipiens molestus (Diptera: Culicidae) in Shanghai, China. J. Med. Entomol. 2019, 56, 656-664. [CrossRef] [PubMed]

47. Apperson, C.S.; Harrison, B.A.; Unnasch, T.R.; Hassan, H.K.; Irby, W.S.; Savage, H.M.; Aspen, S.E.; Watson, D.; Rueda, L.M.; Engber, B.R.; et al. Host-feeding habits of Culex and other mosquitoes (Diptera: Culicidae) in the Borough of Queens in New York City, with characters and techniques for identification of Culex mosquitoes. J. Med. Entomol. 2002, 39, 777-785. [CrossRef] [PubMed]

48. Apperson, C.S.; Hassan, H.K.; Harrison, B.A.; Savage, H.M.; Aspen, S.E.; Farajollahi, A.R.Y.; Unnasch, T.R. Host feeding patterns of established and potential mosquito vectors of West Nile virus in the eastern United States. Vector Borne Zoonotic Dis. 2004, 4 , 71-82. [CrossRef]

49. Molaei, G.; Andreadis, T.G.; Armstrong, P.M.; Anderson, J.F.; Vossbrinck, C.R. Host feeding patterns of Culex mosquitoes and West Nile virus transmission, northeastern United States. Emerg. Infect. Dis. 2006, 12, 468. [CrossRef] [PubMed]

50. Kilpatrick, A.M.; Kramer, L.D.; Jones, M.J.; Marra, P.P.; Daszak, P.; Fonseca, D.M. Genetic influences on mosquito feeding behavior and the emergence of zoonotic pathogens. Am. J. Trop Med. Hyg. 2007, 77, 667-671. [CrossRef]

51. Huang, S.; Hamer, G.L.; Molaei, G.; Walker, E.D.; Goldberg, T.L.; Kitron, U.D.; Andreadis, T.G. Genetic variation associated with mammalian feeding in Culex pipiens from a West Nile virus epidemic region in Chicago, Illinois. Vector Borne Zoonotic Dis. 2009, 9 , 637-642. [CrossRef]

52. Simpson, J.E.; Folsom-O'Keefe, C.M.; Childs, J.E.; Simons, L.E.; Andreadis, T.G.; Diuk-Wasser, M.A. Avian host-selection by Culex pipiens in experimental trials. PLoS ONE 2009, 4, e7861. [CrossRef] 
53. Simpson, J.E.; Hurtado, P.J.; Medlock, J.; Molaei, G.; Andreadis, T.G.; Galvani, A.P.; Diuk-Wasser, M.A. Vector host-feeding preferences drive transmission of multi-host pathogens: West Nile virus as a model system. Proc. Royal. Soc. B 2012, 279, 925-933. [CrossRef]

54. Savage, H.M.; Kothera, L. The Culex pipiens complex in the Mississippi River basin: Identification, distribution, and bloodmeal hosts. J. Am. Mosq. Control Assoc. 2012, 28, 93-99. [CrossRef]

55. Faraji, A.; Gaugler, R. Experimental host preference of diapause and non-diapause induced Culex pipiens pipiens (Diptera: Culicidae). Parasit Vectors 2015, 8, 389. [CrossRef] [PubMed]

56. Kothera, L.; Mutebi, J.P.; Kenney, J.L.; Saxton-Shaw, K.; Ward, M.P.; Savage, H.M. Bloodmeal, host selection, and genetic admixture analyses of Culex pipiens complex (Diptera: Culicidae) mosquitoes in Chicago, IL. J. Med. Entomol. 2020, 57, 78-87. [CrossRef] [PubMed]

57. Klowden, J. Initiation and termination of host-seeking inhibition in Aedes aegypti during oöcyte maturation. J. Insect Phys. 1981, 27, 799-803. [CrossRef]

58. Klowden, J.; Arden, O. Humoral inhibition of host-seeking in Aedes aegypti during oöcyte maturation. J. Insect Phys. 1979, 25, 231-235. [CrossRef]

59. Kassim, N.F.A.; Webb, C.E.; Russell, R.C. Is the expression of autogeny by Culex molestus Forskal (Diptera: Culicidae) influenced by larval nutrition or by adult mating, sugar feeding, or blood feeding? J. Vector Ecol. 2012, 37, 162-171. [CrossRef]

60. Reeves, W.C. Quantitative Field Studies on a Carbon Dioxide Chemotropism of Mosquitoes. Am. J. Trop. Med. Hyg. 1953, 2, 325-331. [CrossRef]

61. Bates, D.; Maechler, M.; Bolker, B. lme4: Linear Mixed-Effects Models Using S4 Classes; R Package: Los Angeles, CA, USA, 2011.

62. Zeileis, A.; Hothorn, T. Diagnostic Checking in Regression Relationships. R News 2, 7-10. 2002. Available online: https: / /CRAN.R-project.org/doc/Rnews/ (accessed on 9 January 2018).

63. Lindsay, S.W.; Adiamah, J.H.; Miller, J.E.; Pleass, R.J.; Armstrong, J.R.M. Variation in attractiveness of human subjects to malaria mosquitoes (Diptera: Culicidae) in The Gambia. J. Med. Entomol. 1993, 30, 368-373. [CrossRef] [PubMed]

64. Qiu, Y.T.; Smallegange, R.C.; Van Loon, J.J.A.; Ter Braak, C.J.F.; Takken, W. Interindividual variation in the attractiveness of human odours to the malaria mosquito Anopheles gambiae ss. Med. Vet. Entomol. 2006, 20, 280-287. [CrossRef]

65. Fritz, M.L.; Walker, E.D.; Yunker, A.J.; Dworkin, I. Daily blood feeding rhythms of laboratory-reared North American Culex pipiens. J. Circadian Rhythms 2014, 12, 1. [CrossRef]

66. Andrews, S. FastQC A Quality Control Tool for High Throughput Sequence Data. 2010. Available online: http://www. bioinformatics.babraham.ac.uk/projects/fastqc/ (accessed on 10 January 2018).

67. Bolger, A.M.; Lohse, M.; Usadel, B. Trimmomatic: A flexible trimmer for Illumina Sequence Data. Bioinformatics 2014, 30, 2114-2120. [CrossRef]

68. Dobin, A.; Davis, C.A.; Schlesinger, F.; Drenkow, J.; Zaleski, C.; Jha, S.; Batut, P.; Chaisson, M.; Gingeras, T.R. STAR: Ultrafast universal RNA-seq aligner. Bioinformatics 2013, 29, 15-21. [CrossRef] [PubMed]

69. Anders, S.; Pyl, P.T.; Huber, W. HTSeq-A Python framework to work with high-throughput sequencing data. Bioinformatics 2015, 31, 166-169. [CrossRef]

70. Gelman, A.; Su, Y. Arm: Data Analysis Using Regression and Multilevel/Hierarchical Models. R Package Version 1.11-2. 2020. Available online: https: / CRAN.R-project.org/package=arm (accessed on 10 January 2020).

71. Love, M.I.; Huber, W.; Anders, S. Moderated estimation of fold change and dispersion for RNA-seq data with DESeq2. Genome Biol. 2014, 15, 550. [CrossRef]

72. Stephens, M. Ashr: Methods for Adaptive Shrinkage, Using Empirical Bayes. R Package Version 2.2-47. 2016. Available online: https:/ /CRAN.R-project.org/package=ashr (accessed on 10 January 2020).

73. Mi, H.; Ebert, D.; Muruganujan, A.; Mills, C.; Albou, L.P.; Mushayamaha, T.; Thomas, P.D. PANTHER version 16: A revised family classification, tree-based classification tool, enhancer regions and extensive API. Nucl. Acids Res. 2020. [CrossRef]

74. Fischer, S.; Brunk, B.P.; Chen, F.; Gao, X.; Harb, O.S.; Iodice, J.B.; Stoeckert, C.J., Jr. Using OrthoMCL to assign proteins to OrthoMCL-DB groups or to cluster proteomes into new ortholog groups. Curr. Protoc. Bioinform. 2011, 35, 6-12.

75. Hamer, G.L.; Kitron, U.D.; Brawn, J.D.; Loss, S.R.; Ruiz, M.O.; Goldberg, T.L.; Walker, E.D. Culex pipiens (Diptera: Culicidae): A bridge vector of West Nile virus to humans. J. Med. Entomol. 2008, 45, 125-128. [CrossRef] [PubMed]

76. Hamer, G.L.; Kitron, U.D.; Goldberg, T.L.; Brawn, J.D.; Loss, S.R.; Ruiz, M.O.; Hayes, D.; Walker, E.D. Host selection by Culex pipiens mosquitoes and West Nile virus amplification. Am. J. Trop. Med. Hyg. 2009, 80, 268-278. [CrossRef] [PubMed]

77. Gillies, M.T. Experiments on host selection in the Anopheles gambiae complex. Ann. Trop. Med. Parasit. 1967, 61, 68-75. [CrossRef] [PubMed]

78. Mukwaya, L.G. Genetic control of feeding preferences in the mosquitoes Aedes (Stegomyia) simpsoni and aegypti. Physiol. Entomol. 1977, 2, 133-145. [CrossRef]

79. McBride, C.S. Genes and odors underlying the recent evolution of mosquito preference for humans. Curr. Biol. 2016, 26, R41-R46. [CrossRef] [PubMed]

80. Uchida, K.; Ohmori, D.; Yamakura, F.; Suzuki, K. Changes in free amino acid concentration in the hemolymph of the female Culex pipiens pallens (Diptera: Culicidae), after a blood meal. J. Med. Entomol. 1990, 27, 302-308. [CrossRef]

81. Sterkel, M.; Perdomo, H.D.; Guizzo, M.G.; Barletta, A.B.F.; Nunes, R.D.; Dias, F.A.; Sorgine, M.; Oliveira, P.L. Tyrosine detoxification is an essential trait in the life history of blood-feeding arthropods. Curr. Biol. 2016, 26, 2188-2193. [CrossRef] [PubMed] 
82. Wang, W.; Wu, Z.; Dai, Z.; Yang, Y.; Wang, J.; Wu, G. Glycine metabolism in animals and humans: Implications for nutrition and health. Amino Acids 2013, 45, 463-477. [CrossRef]

83. Isoe, J.; Scaraffia, P.Y. Urea synthesis and excretion in Aedes aegypti mosquitoes are regulated by a unique cross-talk mechanism. PLOS ONE 2013, 8, e65393. [CrossRef]

84. Leal, W.S.; Choo, Y.M.; Xu, P.; da Silva, C.S.; Ueira-Vieira, C. Differential expression of olfactory genes in the southern house mosquito and insights into unique odorant receptor gene isoforms. Proc. Natl. Acad. Sci. USA 2013, 110, 18704-18709. [CrossRef]

85. Taparia, T.; Ignell, R.; Hill, S.R. Blood meal induced regulation of the chemosensory gene repertoire in the southern house mosquito. BMC Genom. 2017, 18, 393. [CrossRef]

86. Isoe, J.; Petchampai, N.; Isoe, Y.E.; Co, K.; Mazzalupo, S.; Scaraffia, P.Y. Xanthine dehydrogenase-1 silencing in Aedes aegypti mosquitoes promotes a blood feeding-induced adulticidal activity. FASEB J. 2017, 31, 2276-2286. [CrossRef]

87. Mattila, J.; Hietakangas, V. Regulation of carbohydrate energy metabolism in Drosophila melanogaster. Genetics 2017, 207, 1231-1253.

88. Beckstead, R.B.; Lam, G.; Thummel, C.S. The genomic response to 20-hydroxyecdysone at the onset of Drosophila metamorphosis. Genome Biol. 2005, 6, R99. [CrossRef] [PubMed]

89. Hagedorn, H.H.; O'Connor, J.D.; Fuchs, M.S.; Sage, B.; Schlaeger, D.A.; Bohm, M.K. The ovary as a source of alpha-ecdysone in an adult mosquito. Proc. Natl. Acad. Sci. USA 1975, 72, 3255-3259. [CrossRef]

90. Dhara, A.; Eum, J.H.; Robertson, A.; Gulia-Nuss, M.; Vogel, K.J.; Clark, K.D.; Strand, M.R. Ovary ecdysteroidogenic hormone functions independently of the insulin receptor in the yellow fever mosquito, Aedes aegypti. Insect Biochem. Mol. 2013, 43, 1100-1108. [CrossRef] [PubMed]

91. Gulia-Nuss, M.; Eum, J.H.; Strand, M.R.; Brown, M.R. Ovary ecdysteroidogenic hormone activates egg maturation in the mosquito Georgecraigius atropalpus after adult eclosion or a blood meal. J. Exp. Biol. 2012, 215, 3758-3767. [CrossRef]

92. Liu, C.; Pitts, R.; Bohbot, J.; Jones, P.; Wang, G. Distinct olfactory signaling mechanisms in the malaria vector mosquito Anopheles gambiae. PLoS Biol. 2010, 8, e72595. [CrossRef] [PubMed]

93. Syed, Z.; Leal, W.S. Acute olfactory response of Culex mosquitoes to a human- and bird-derived attractant. Proc. Natl. Acad. Sci. USA 2009, 106, 18803-18808. [CrossRef] [PubMed]

94. Price, D.C.; Fonseca, D.M. Genetic divergence between populations of feral and domestic forms of a mosquito disease vector assessed by transcriptomics. PeerJ 2015, 3, e807. [CrossRef]

95. Hill, S.R.; Ghaninia, M.; Ignell, R. Blood meal induced regulation of gene expression in the maxillary palps, a chemosensory organ of the mosquito Aedes aegypti. Front. Ecol. Evol. 2019, 336. [CrossRef]

96. Anholt, R.R.H. Chemosensation and evolution of Drosophila host plant selection. IScience 2020, 23, 100799. [CrossRef]

97. Clyne, P.J.; Warr, C.G.; Freeman, M.R.; Lessing, D.; Kim, J.; Carlson, J.R. A novel family of divergent seven-transmembrane proteins: Candidate odorant receptors in Drosophila. Neuron 1999, 22, 327-338. [CrossRef]

98. Freeman, E.G.; Dahanukar, A. Molecular neurobiology of Drosophila taste. Curr. Opin. Neurobiol. 2015, 34, 140-148. [CrossRef] [PubMed]

99. Martin-Martin, I.; Paige, A.; Leon, P.C.V.; Gittis, A.G.; Kern, O.; Bonilla, B.; Chagas, A.C.; Ganesan, S.; Smith, L.B.; Garboczi, D.N.; et al. ADP binding by the Culex quinquefasciatus mosquito D7 salivary protein enhances blood feeding on mammals. Nat. Commun. 2020, 11, 2911. [CrossRef] [PubMed] 